\title{
Loxoscelismo: Comentario editorial
}

$\mathrm{L}$ a revisión sistemática orientada a evaluar la efectividad de diversos tratamientos utilizados en el manejo del loxoscelismo cutáneo y cutáneo visceral, producido por la mordedura de arañas del género Loxosceles presentada en este número por los Dres. Manríquez y Silva, sin lugar a dudas constituye un muy buen ejemplo de búsqueda de la mejor evidencia científica disponible para el manejo de esta patología.

Si bien los resultados obtenidos no nos proporcionan ninguna evidencia científicamente sustentable, este hecho no nos debe llamar mucho la atención, fundamentalmente por tres razones: la primera, por tratarse de una patología que constituye una emergencia, tal como lo demuestran la caracterización clínico-epidemiológica de llamadas telefónicas por esta posible afección a un centro de información toxicológica y las diversas casuísticas que analizan el lugar de consulta de la mayoría de estos pacientes, no existiendo un centro especializado de consulta de esta patología. La segunda, por no existir relación del daño local que se puede producir por la acción del veneno en los distintos pacientes, siendo mínimo o de tipo edematoso en algunos y necrótico y extenso en otros. Por último, la falta de métodos diagnósticos de certeza de la lesión (ejemplo: identificación local de la esfingomielinasa D) así como de la araña, al no disponer de entomólogos de fácil accesibilidad.

Por esta razones es difícil realizar ensayos clínicos de cualquier tipo, o estudio de casos y controles frente a una patología que implica, en algunos casos, un riesgo de muerte y cuyo énfasis debe estar puesto en la prevención de este accidente, en la consulta oportuna ante la sospecha, en el diagnóstico adecuado y en las acciones inmediatas que se deben tomar. Sin embargo, no nos debe quedar la impresión de que ningún tratamiento es adecuado.

Este accidente se previene realizando un aseo profundo y periódico, al menos cada seis meses, de las habitaciones de una casa, por tratarse de una araña de reproducción lenta y ocultarse detrás de muebles, cuadros, repisas, o dentro de los closets. El no dejar las camas pegadas a la pared durante la noche o ropa colgada en los muros son medidas que se pueden adoptar con facilidad, recordando que es una araña de hábitos alimentarios nocturnos.

El público en general debiera familiarizarse más en el reconocimiento de esta araña que es bastante común en los domicilios y en los síntomas inmediatos que produce. El dolor intenso y permanente que produce la mordedura inmediatamente o a los pocos minutos en la mayoría de los casos, más aún si ocurre de noche y despierta al paciente, o al colocarse la ropa que quedó colgada, debiera ser un signo de alarma para consultar precozmente. El uso de frío local parece ser una medida útil, tal como lo señalan los autores, para evitar la diseminación del veneno.

El diagnóstico se basa fundamentalmente en los antecedentes epidemiológicos y en el aspecto que la lesión va adquiriendo con el transcurso de las horas, desde una placa eritemato-violácea edematosa hasta la formación de la lesión característica de tipo livedoide, con o sin flictenas claras o hemorrágicas, rodeada de un halo eritematoso muy doloroso, cuando evoluciona hacia la forma necrótica. Sin embargo, no se debe esperar la aparición de esta lesión característica para sospechar el diagnóstico.

Frente al posible diagnóstico sustentado en lo comentado en los párrafos precedentes, lo primero que se debe hacer es solicitar un examen microscópico de orina y calmar el dolor. La aparición de hematuria microscópica nos obliga a hospitalizar al paciente en una unidad de cuidados intensivos porque estamos frente a un loxoscelismo con compromiso visceral. Si el examen de orina es normal, debemos calmar el dolor, disminuir el edema y la inflamación. Los antihistamínicos y el uso de corticosteroides han sido utilizados empíricamente en este sentido, con algún tipo de evidencia el primero de ellos. Dapsona no es un medicamento disponible en los servicios de urgencia, en la práctica es manejado por el especialista en dermatología. El control dentro de las 24 horas siguientes es fundamental y con un nuevo examen de orina. Si éste resulta normal se puede descartar el compromiso sistémico y suspender los corticosteroides porque, tal como lo señalan los autores, han demostrado retrasar la cicatrización.

Patricia Muñoz C. del V. Facultad de Medicina Universidad Diego Portales 